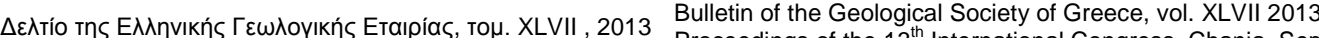

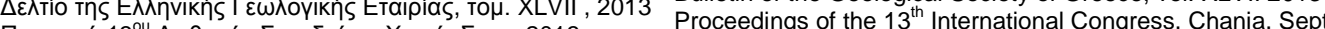

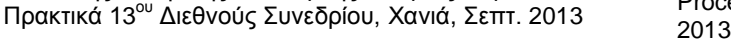

\title{
ENGINEERING GEOLOGICAL BEHAVIOUR OF RECENT CONGLOMERATE DEPOSITS IN DAM FOUNDATION. THE CASE OF AGIOKAMPOS DAM IN THESSALY, CENTRAL GREECE
}

\author{
Marinos V. ${ }^{1}$, Lazaridou S. ${ }^{2}$, Perleros V. ${ }^{3}$ and Sotiropoulou K. ${ }^{4}$ \\ ${ }^{1}$ Aristotle University of Thessaloniki, Faculty of Sciences, School of Geology, Division of. \\ Geology,marinosv@geol.auth.gr, \\ ${ }^{2}$ Hydroexigiantiki Cons.Engineers, Evias 3, 15125 Athens, Greece \\ ${ }^{3}$ Perleros V., Geologist, Dionysou 56, 152 34, Halandri, Greece \\ ${ }^{4}$ Sotiropoulou K., Geologist, Miaouli 18 Kifisia, 145 61, Kifissia, Greece
}

\begin{abstract}
A typical example of dam foundation on Neogenic conglomerate deposits is presented in this paper. The case of Agiokampos dam in east Thessaly in central Greece. The level of natural compactness and the nature of the cementing material are crucial elements for the strength, the bearing capacity and the permeability of these formations. These conglomerates of medium consistency, do not allow relying on traditional sampling and tests in the boreholes. Lugeon tests are meaningless and falling head tests are recommended. Back analysis on slopes is certainly a useful tool for approaching the strength parameters of the global rock mass. Thus it is understood that the engineering geological assessment before any testing and analysis is of prime importance.

Due to the fine nature of the cement, permeability is generally low and no leakages are expected. However, an impermeable grout curtain must be created due to some higher values. Conglomerates are not easily groutable and a combination of a diaphragm wall is suggested. Finally, a carpet grouting is designed since the surficial zone is susceptible to internal erosion.
\end{abstract}

Key words: conglomerates, earthfill dam, foundation, permeability, water tightness.

\section{Пєрí $\eta \psi \eta$}

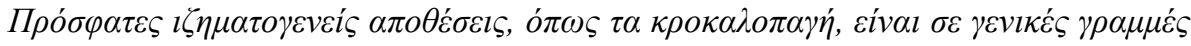

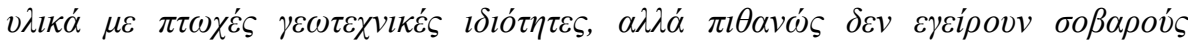

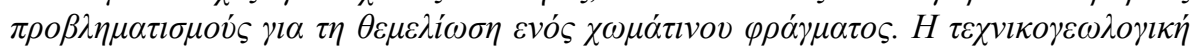

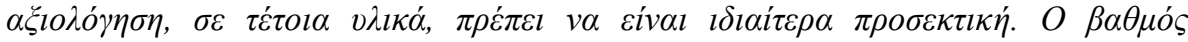

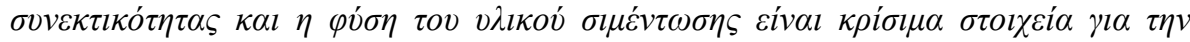

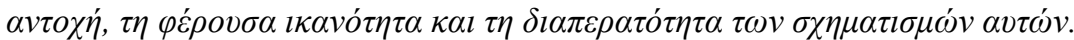

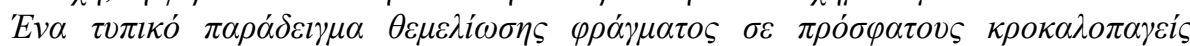

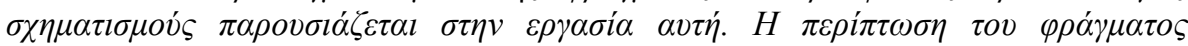

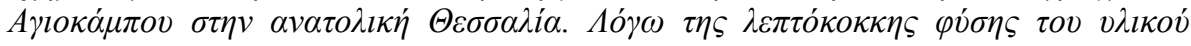

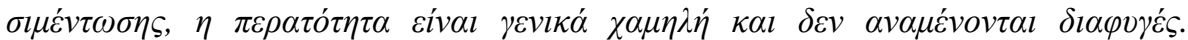

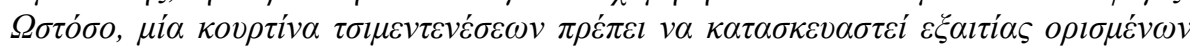

$\underline{\text { XLVII, No } 3-1759}$ 


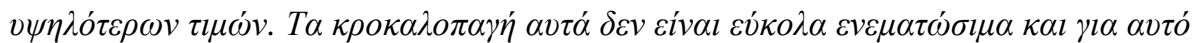

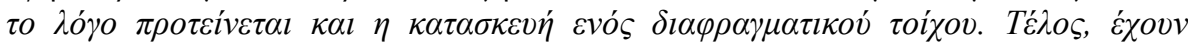

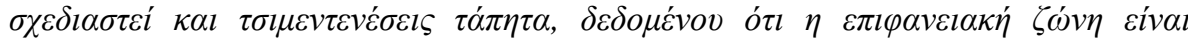

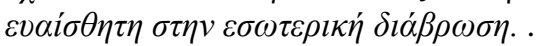

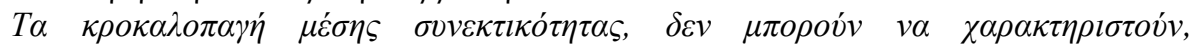

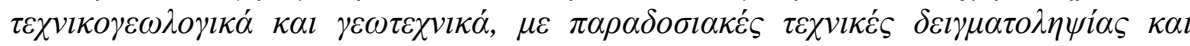

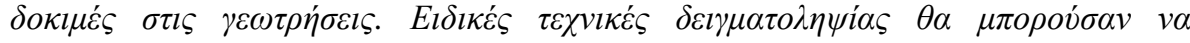

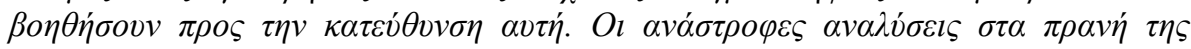

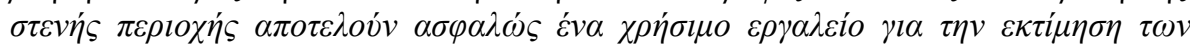

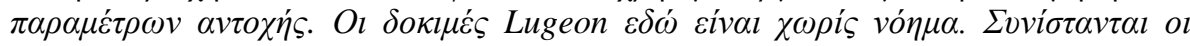

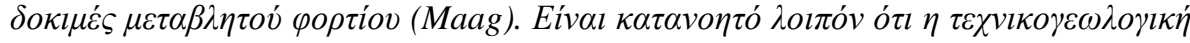

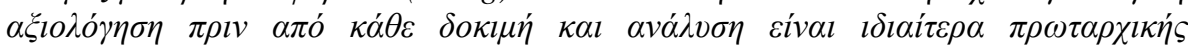

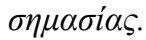

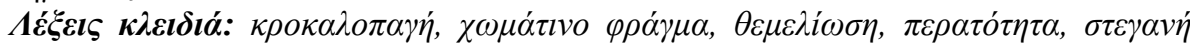

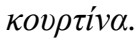

\section{Introduction}

The Agiokampos dam is studied to be constructed in the eastern part of the prefecture of Larissa on Pouri stream about 3,7 km from its mouth. In Pouri stream 2 branches are met, where their runoff is enhanced by the discharges of several springs from the southern edge of Ossa and Mavrovouni mountains. The area belongs to both municipalities of Agia and Larissa. The project, supervised by Hellenic Ministry of Rural Development and Food and funded by the NSRF, is under the final study, since the technical preliminary design has been recently submitted.

The catchment area is $75 \mathrm{~km}^{2}$, while the inundation area is $0,61 \mathrm{~km}^{2}$. The dam is constructed for irrigation purposes. It will have a maximum height of $37,5 \mathrm{~m}$ with a reservoir net capacity of 4.4 $\mathrm{km}^{2}$. The elevation of the river at the central cross-section of the dam is at $+32,5 \mathrm{~m}$, while the maximum altitude of the basin is $1182 \mathrm{~m}$. The dam foundation is placed around $250 \mathrm{~m}$ downstream of the junction of the two main branches of the stream. The width of the riverbed at the site of the dam is approximately $100 \mathrm{~m}$.

In the wider zone of the riverbed a fluvial terrace is developed with a difference in height up to $7 \mathrm{~m}$ from the present riverbed, an indication of upward tectonic movements in the region. The riverbed is confined by steep slopes, which in the area of the dam reach the heights of $30 \mathrm{~m}$ in the left abutment and about $12 \mathrm{~m}$ in the right. At the higher parts of the basin, mild slope surfaces are developed (flattening planes) of varying size, on which red clays and sands are present. The basis of these deposits consists a characteristic palaeorelief. These surfaces are believed to be associated with tectonic terraces.

The geological context of the broader region of the Agiokampos dam is of the Pelagonian series, consisting of metamorphic rocks, covered by recent Neogene and alluvial deposits. These Pelagonian series, encountered in the wider region of Eastern Thessaly, are represented here with crystalline schists, phyllites, gneisses, amphibolites, and marbles often in alternating units, while ophiolites are present (Geological map of Greece, 1:50000, Sheet Ayia-Panayia Ayias, see also Stamatis and Miggiros, 2004). At the base of the whole area schists are encountered with frequent intercalations of ankeritic marbles, as isolated lenses though. The formations that are specifically met in the inundation area are the medium-thick-bedded marbles (Cretaceous), which are intensely karstified and fractured with intercalations of crystalline dolomite. They are found in the Monastery of Sts. Anargiron at the tail of the inundation area. Schists are outcropping just downstream of the dam foundation on the right abutment. These formations have been also met in the borehole drillings below the dam foundation as the bedrock over which the Neogene formations were deposited. A simplified geological map of the inundation area (a) and the dam

XLVII, No $3-1760$ 
axis (b) is presented in Figure 1. The geological formations of the foundation zone are described in more detail in the next paragraph.

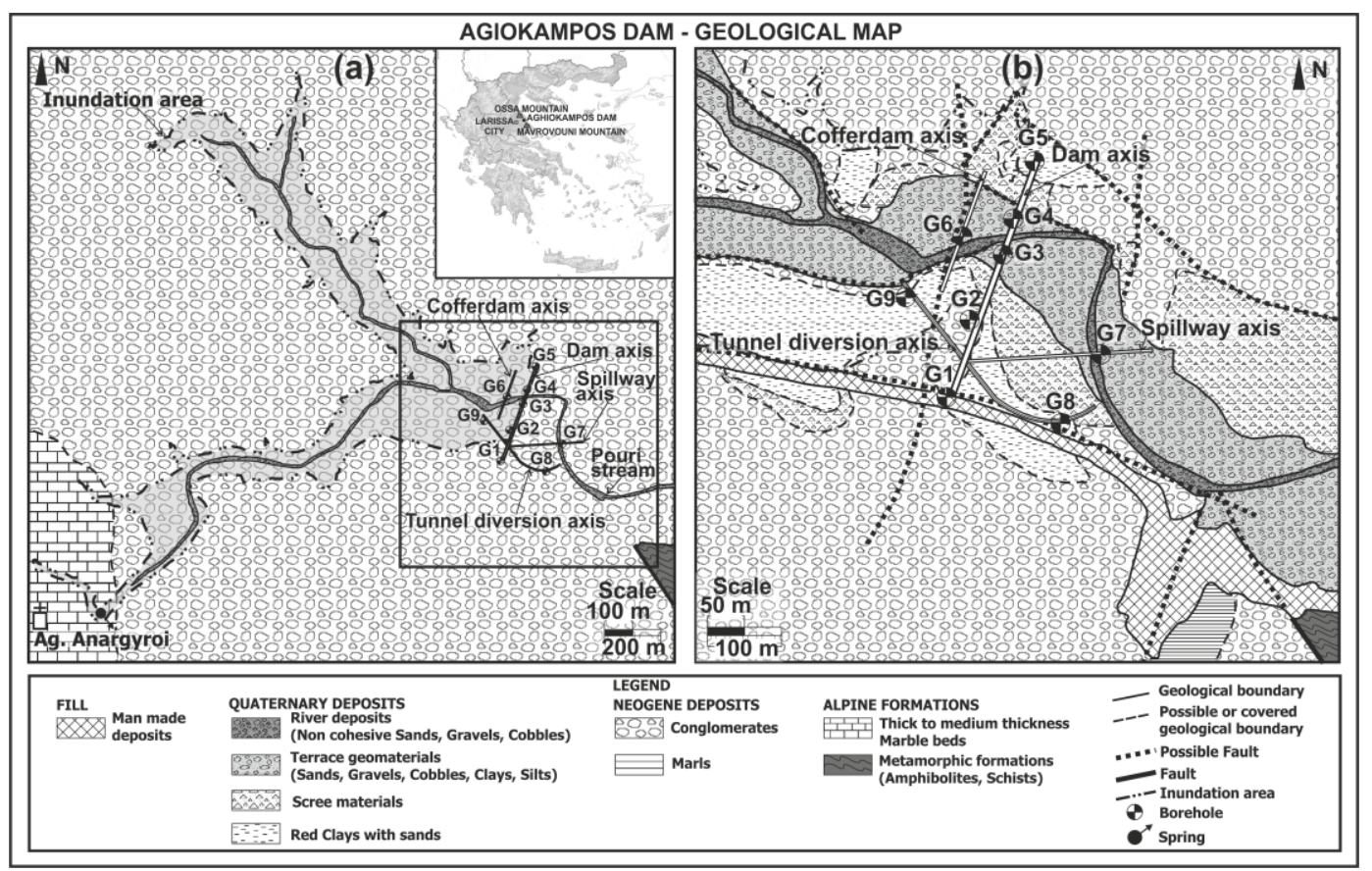

Figure 1 - (a) Geological map along the inundation area of Agiokampos Dam, (b) Geological map along the Agiokampos Dam axis.

\section{Geological Conditions Along the Dam Axis}

\subsection{Lithological Conditions}

Neogene formations, possibly extending to the Pleistocene, cover almost the whole studied area. The formations consist of conglomerates (containing also angular fragments of rocks) with irregular torrential structure, although bedding is frequently developed. Siltstones, sandstones and marls are also encountered in places, as lenses or irregular beds, in the conglomeratic environment. Their thickness is exceeding $300 \mathrm{~m}$. The cementation material is mostly silty-sandy and only in places can be characterized as clayey. The conglomerates are medium to fairly strong cemented. The deposits have experienced significant tectonic uplift and have a monoclinic structure.

Terrace deposits are also encountered and they are developed 15-20m higher than the present riverbed. They mainly include sands, pebbles, gravel with some silty clays. Their thickness reaches $7-8 \mathrm{~m}$. Scree materials and the elluvial weathered zone of conglomerates cover the slopes. They involve loose materials of clays, sands and pebbles and their thickness can reach $5 \mathrm{~m}$. The recent river deposits involve loose materials, which include pebbles, cobles mainly from marbles and ultramafic rocks and sands. Finally, man made deposit are only found in borehole G1 with thickness $1-2 \mathrm{~m}$.

\subsection{Tectonic Conditions}

The development of basins or troughs in the area of Thessaly started on Miocene with faults of NNE-SSW and E-W direction (Stamatis and Migkiros, 2004, Caputo and Pavlides, 1991). The primary deformation NNE-SSW is connected with structures, thrusts and faults and the secondary E-W with direction faults. Characteristic of the tectonics in the studied area is the presence of troughs of E-W direction transversal of the directions of the Tempi valley and the Anavra - Agia 
basin forming the basins of lacustrine and continental sediments. The $\mathrm{E}-\mathrm{W}$ fault system, despite being a secondary one in the region, is greatly expressed forming well-distinguished morphological reliefs. In the foundation zone of the dam it is estimated that the riverbed zone is defined by two faults that have allowed the formation of the steep slopes of the area. The action of these two faults has contributed to a local fracturing of the conglomerates, met in the exploratory drilling. This neotectonic setting is also the reason of the inclination of the Neogene strata.

In the left abutment, immediately upstream of the dam axis, the possible position two faults are noted along the local streams. Few collapses and landslides occur on slopes along the streams that may be linked to the fault activity and deep erosion. From the seismotectonic study of the dam design (by and Prof. E. Papadimitriou and Ass. Prof V. Karakostas of the University of Thessaloniki), it was revealed that there is no further evidence of activity of these faults. It is recommended however to provide those features in the design of the dam, such as thick filters, in order to face a potential displacement along the faults in earthquake. This potential should be nevertheless low in the area.

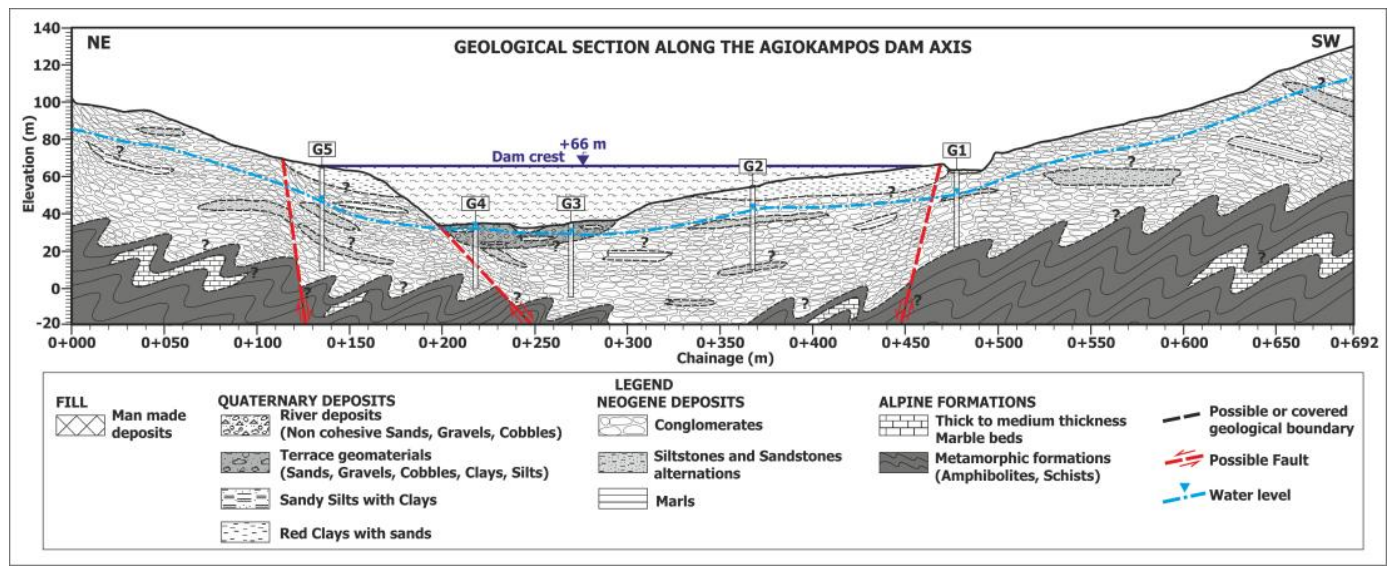

Figure 2 - Geological section along the axis of Agiokampos Dam.

\section{Engineering Geological Conditions}

\subsection{General}

The engineering geological assessment for a proper geotechnical design of a dam, on such materials, must be very careful since the usual tools of geotechnical characterization cannot be easily applied here. This is due to the nature of the materials, that either they fall on the hard soil or the weak rock margin. The level of natural compactness and the nature of the cementing material are crucial elements for the strength, the bearing capacity and the permeability of these formations.

In order to investigate the engineering geological and geotechnical conditions of the dam and the appurtenant structures (spillway, diversion tunnel, cofferdam), a site investigation program was performed. The evaluated data were provided from field observations and geological mapping, from the results of boreholes ( 9 boreholes) and from in situ and laboratory tests. Specifically, the data used were surface observations of bedrock exposures, slope stability features depending on the nature of the ground, permeability values, rock quality designation index (RQD), standard penetration test values (SPT), and physical characteristics. These parameters were to be evaluated for the geotechnical description of the formations and subsequently, the assessment and proposal of geotechnical parameters of the geomaterials. 


\subsection{Engineering Geological Conditions of the Dam Axis}

The conglomerates in the left abutment of the dam are found with higher presence of finer siltysandy materials while more systematic presence of pebbles exists in the right one. A typical stratigraphic image of the left and right abutment is shown in Figures $3 \mathrm{a}$ and $3 \mathrm{~b}$ respectively. The layers present a moderate inclination to the N-NS, without forming however practicable sliding planes. The slopes are generally homogeneous and they do not show clear variations in strength. Although the conglomerates are globally homogeneous, alternations of fine-grained and coarse layers are present. Note that the left abutment, though steeper in slope, presents several phenomena of erosion. On the other hand, at the base of the slope, near the riverbed, the conglomerates occur with increased consistency due to calcitic presence. Conglomerates are not very cohesive close to the surface but soon, in small depth, they become more compact, at an acceptable level for bearing an earth structure of the size of this dam.

Recent deposits, on terraces and of clay nature, are overlying these materials. Terrace deposits are generally soft, of low consistency and they must be removed for the foundation of the dam, while they can be used for the core of the dam.
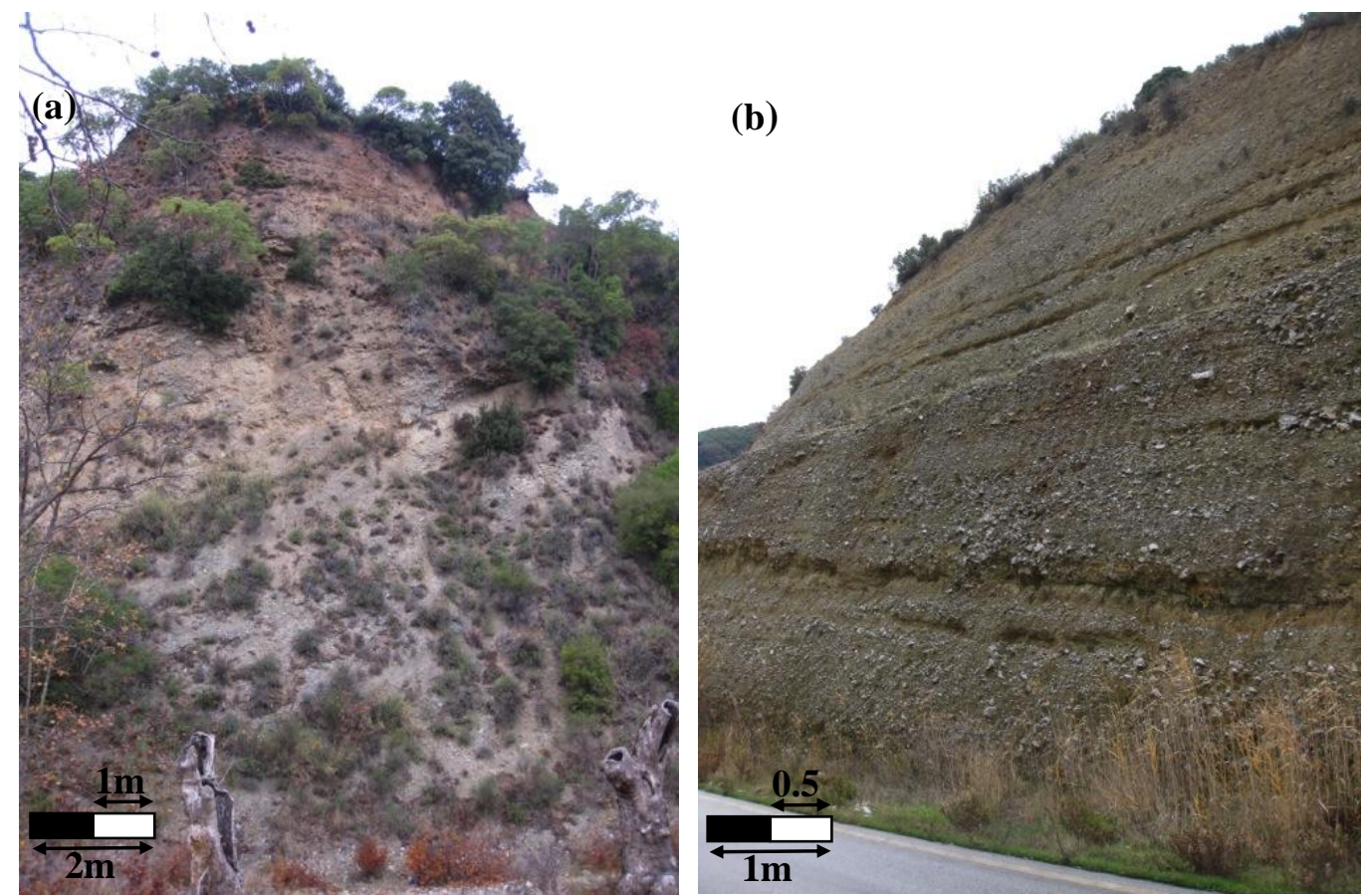

Figure 3 - Typical series of the formation at the left (a) and right (b) abutment of the dam. Conglomerates are met here with a high presence of fine, silty-sandy, materials in the left a butment, while in the right one there is more systematic presence of pebbles. The formatio ns show moderate consistency but good friction angle, due to the interlocking of the granul ar materials, since they form steep and high slopes.

The nature of soil formations, along the axis of the dam, based on the description of drilled cores as classified by the USCS classification, is sandy-gravelly. However, the recorded permeability values (Figure 6,7) are quite low for such formations. The presence of fine material in the matrix is the reason for the low permeability measured. This fine material, seen at the outcrops was probably wash out during drilling and thus a misleading on interpretation in such material is possible. On the other hand, such a loss of fine material during drilling in the conglomerates probably indicates a moderate consistency of this geomaterial. Improvement of sampling procedure in bore- 
holes is difficult in such ground, thus the engineering geological judgement from the appearance in outcrops is essential.

Regarding the assessment of rock mass quality with the RQD index, the following notes must be highlighted. The RQD should be marginally only used for post-alpine formations and for weak rocks which have not been fractured due to tectonism, stress relief or weathering. The RQD values here range from zero up to about $75 \%$, if strictly considered (Figure 4). The "disorganized structure" as shown in the cores is certainly due to the disturbance and washing out of fine material during drilling and sampling, provoking a collapse of the rock mass. Larger values of RQD were recorded mainly in sandstone and mudstone layers within the formation of conglomerates, but these zones are only sporadic. Furthermore, there is no significant change of values with depth. This is normal, as RQD rating does not represent here the logic of reducing the fragmentation due to tectonism or weathering by the increased confinement in depth.

Regarding the distribution of standard penetration test $\left(\mathrm{N}_{\mathrm{SPT}}\right)$ values along the axis of the dam (Figure 4), most of these tests have moderate $\left(\mathrm{N}_{\mathrm{SPT}}=16-30\right)$ to high values $\left(\mathrm{N}_{\mathrm{SPT}}=31-50\right)$ or even refusals (Figure 4). These values are typical of the consistency of the formations present, while refusals may be due to the systematic presence of pebbles, gravels and boulders in the conglomeratic mass.

Thus RQD or SPT tests are useless to apply since the recovered cores have very poor structure easily disintegrated (RQD's $=0$ ) or coarse fractions providing refusals on penetration values. The series of these weak formations are not expected however to be liable to significant compression and subsidence, provided the upper loose zone is defined and removed.

The sampling in these materials must be carefully executed so to allow the maintenance of the sample undisturbed in the form of a core. A double or even triple split core barrel is required for this reason. Exploratory trenches or wells and, in case of major need of information; adits offer a better source in the site investigation procedure.

\section{Type of Dam and Construction Materials}

The appropriate type of dam to be constructed in these geological conditions with formations of moderate consistency and (although not important) heterogeneity is an earthfill one. The solution of a hard embankment is not considered feasible because of the moderate strength of the conglomeratic formation, lied in the foundation zone.

For the construction of this type of dam no major excavation for the foundation is required while it can accommodate deformations and displacements in case of an earthquake activity. Based on the material needs, a geological survey was conducted in the inundation area and the broader basin to find the necessary quantities of suitable construction materials.

Materials for the core were found in locations within the Neogene deposits including marly materials and in clays in the terrace deposits. In case of insufficient quantities of clay, the solution of an impermeable membrane could be considered, either on the upstream face or inside the mass of the dam (Schleiss and Pougatssch, 2010).

For the shells of the embankment the granular materials from both the riverbed and the conglomerates are most suitable (Figure 5). Materials for the filters - drains may easily be derived from the riverbed, and the terraces, after appropriate screening to remove the fine clay fraction. As far as the riprap and paving materials is concerned, sizeable boulders of high strength may be obtained from the outcrops of marbles or fresh gneisses and amphibolites. No suitable material was found though within the inundation area and areas beyond it were examined.

Materials suitable for concrete aggregates within the area of the dam can be derived from the outcrops of marbles. These outcrops though are part of the Natura area located near the Monastery of Agion. Anargyron. Positions outside this area were studied, while there is also the possibility to use riverbed boulders or the conglomerates after the appropriate check that harmful materials, as cherts, are not contained.

$\underline{\text { XLVII, No } 3-1764}$ 


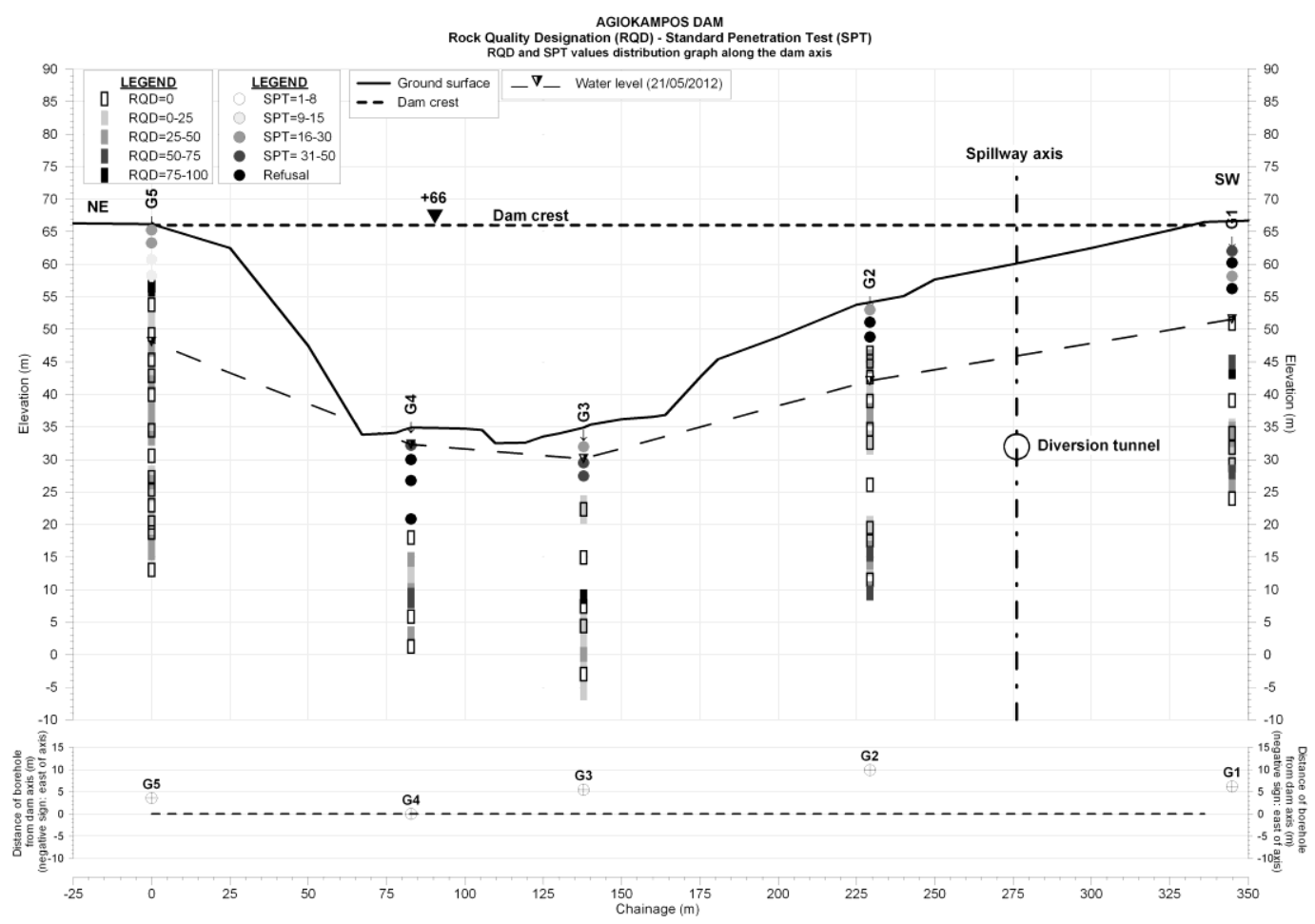

Figure 4 - RQD and $\mathrm{N}_{\mathrm{SPT}}$ values along the Agiokampos Dam axis. The RQD can be marginally used for post-alpine, formations and weak rocks which have not been fractured due to tectonism, stress relief or weathering. The RQD values here range from zero up to about $75 \%$. The "disorganized structure" as shown in the cores is certainly due to the disturbance and washing out of fine material during drilling and sampling provoking a collapse of the rock mass.

(a)

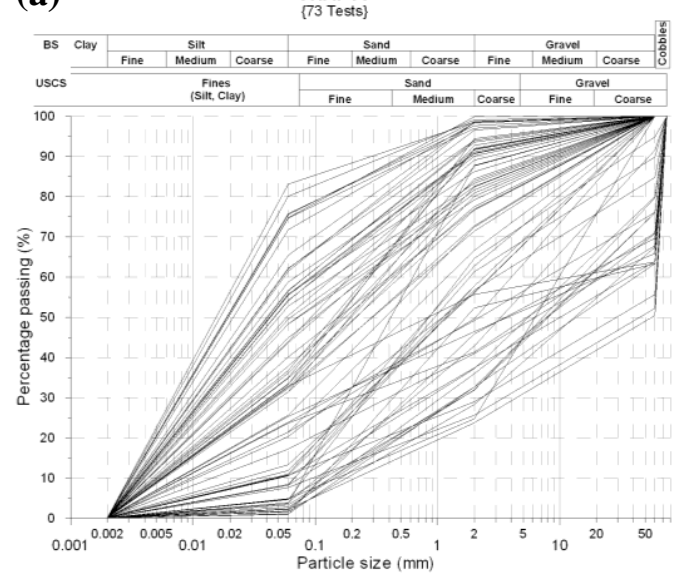

(b) DAM AGIOKAMPOS

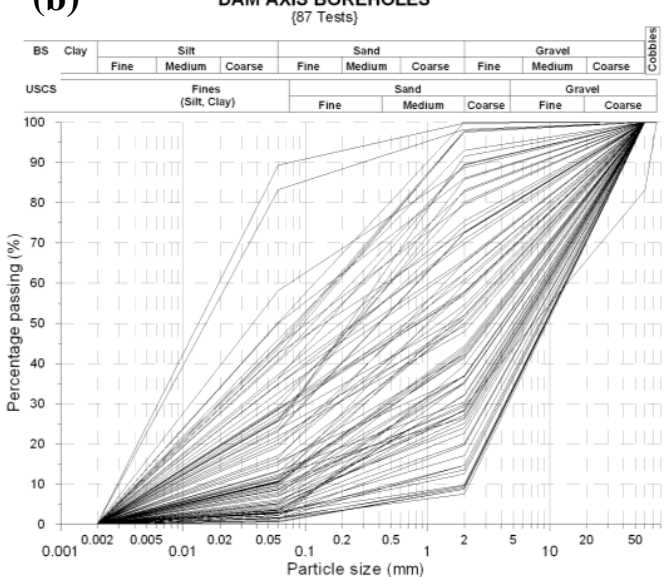

Figure 5 - a: Particle size distribution of the investigated shafts for the shells and filtersdrains of the embankment of Agiokampos dam, b: Particle size distribution of the borehole samples along the dam axis 


\section{Hydrogeological Conditions. Water Tightness and Risk of Erosion}

The dam axis and the inundated basin are covered by the conglomerate formations, which are impermeable in the big scale, excluding their surficial part. In the inundation area there are also limestones, in a short extent; they are permeable but their lowest outcropping point is inside the inundation area, in the stream of Agion Anargiron monastery. Springs are discharged at this point.

The hydrogeological conditions, water tightness and risk of erosion for the dam axis are presented in detail in this study. In situ permeability tests, mainly of falling head (commonly called Maag test), were performed in 5 boreholes. We do not recommend Lugeon tests, as usually applied (Houlsby, 1976), since even moderate pressures disintegrate this kind of rock. The distribution of the permeability $(\mathrm{K})$ values along the axis of the dam is presented in Figure 6. Due to the fine nature of the cement material of the conglomerates, permeability at the abutments is low to very low ( $\mathrm{K}$ about $10^{-7} \mathrm{~m} / \mathrm{sec}$ ) and no leakages are expected under the dam foundation zone or from the future reservoir. It is highlighted that the ground water level in the boreholes is always higher than the riverbed, meaning that the water table in the abutments is drained towards it. Thus no lateral deep drainage exists. This piezometric surface has a trend to reach elevations higher than the future reservoir level (Figure 6). This situation will not necessitate a significant extension of the grout curtain. The presence of some local small springs or permanent moisture higher than the elevation of the riverbed indicates the existence of local horizons with higher individual permeability forming weak perched aquifers.

The distribution of permeability values $(\mathrm{K})$ with depth is shown in Figure 7. The higher values $\left(\sim 10^{-3} \mathrm{~m} / \mathrm{sec}\right)$ are found in the riverbed materials to about $10-12 \mathrm{~m}$ depth, while high values appear in a zone at the left abutment at around $25 \mathrm{~m}$ of depth. Hence, there is an apparent need to address the high permeability of the bed material by removal. However, locally below the dam axis, there are variations in $\mathrm{K}$ values, with the higher ones being in the order of $10^{-3} \mathrm{~m} / \mathrm{sec}$ (in a depth of 10 -

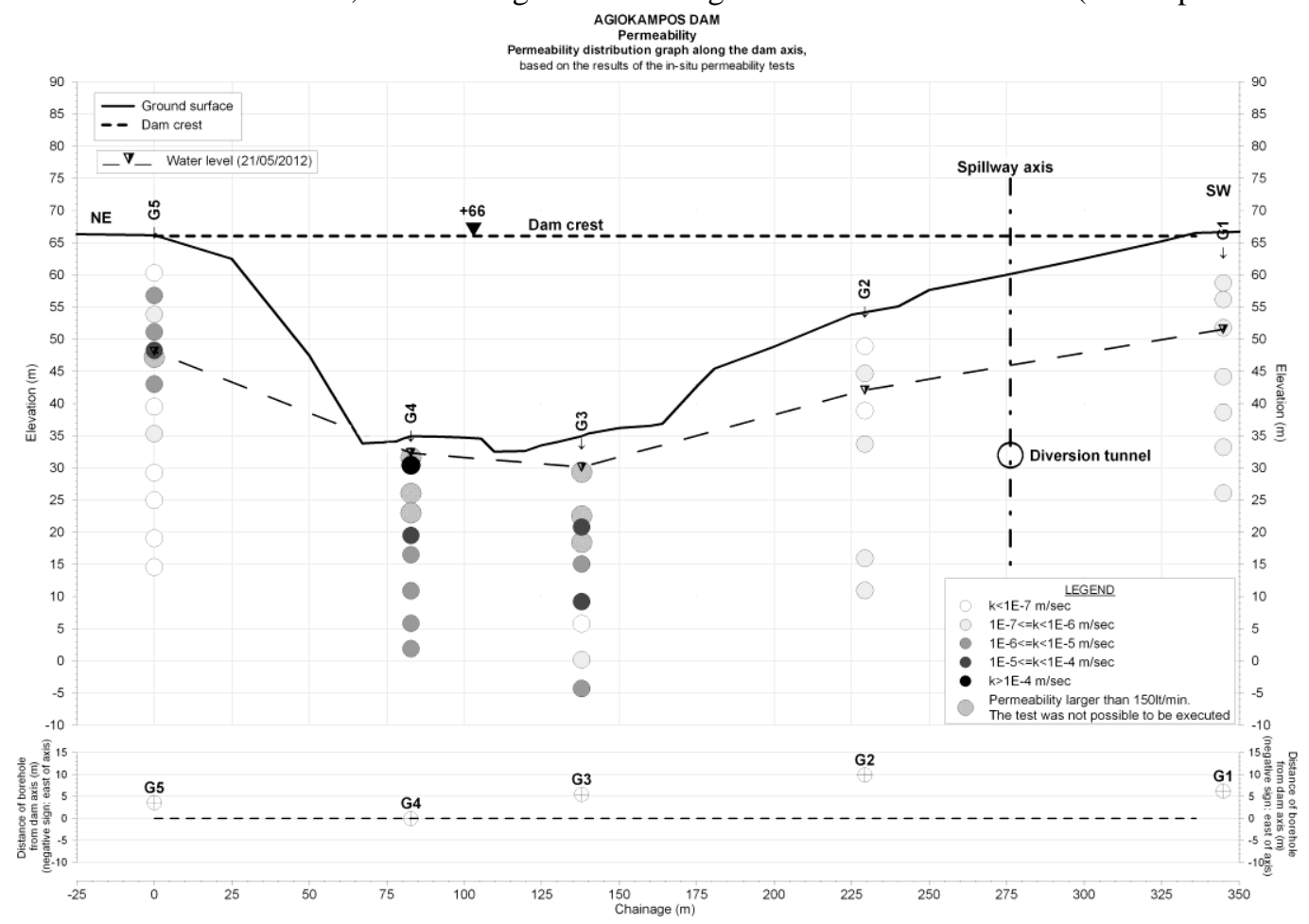

Figure 6 - Distribution of the permeability $(K)$ values along the axis of the dam.

$\underline{\text { XLVII, No } 3-1766}$ 


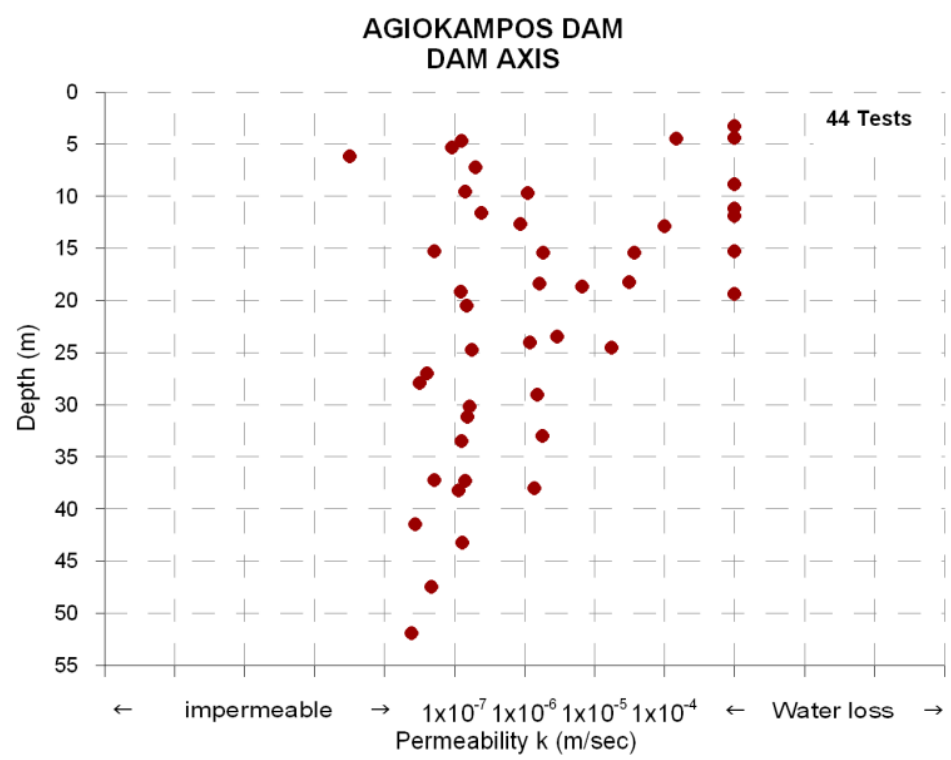

Figure 7 - Distribution of permeability values $(K)$ with depth.

$20 \mathrm{~m}$ depth in borehole G5 and of 18-25m in borehole G3). These high values are possibly associated with weak cementation of the rock mass. Thus, based on the results of the in situ permeability tests it is necessary to construct a grout curtain, having although a moderate depth.

Given the variation of consistency and compactness of the conglomerates, the possibility achieving an effective penetration and sealing in all parts under the dam foundation, if grout injections holes are to be used, should be of concern. Thus a combination with a diaphragm wall could be the solution. Finally given the medium cementation, erosion mechanism can develop, under the hydraulic gradient that will develop with the creation of the reservoir. The implementation of a carpet grouting is thus essential.

\section{Conclusions}

The engineering geological assessment and behaviour of recent conglomerates in dam foundation is presented in the paper. The case of the design of Agiokampos dam, where the conglomerates persist, is studied here. The particular issue in the case of a dam in such rock mass, of conglomerate of medium consistency, is that this material does not allow relying on traditional sampling and tests in the boreholes. Lugeon tests are meaningless and falling head tests are recommended. In order to get the geotechnical parameters, special sampling procedures are required. Deep trenches and adits allow more reliable observation and certainly representative sampling. Back analysis on slopes is without doubt a useful tool for approaching the strength parameters of the global rock mass. Thus it is understood that the engineering geological assessment before any testing and analysis is of prime importance.

The conglomerates in the area of study have clayey or sandy-silty matrix and generally show medium consistency with generally good interlocking between the pebbles. The material, geotechnically speaking, is weak but it does not raise serious concerns for the foundation of an earthfill dam. It has low strength but low compressibility against settlement. The bedrock of the conglomerate formation is crystalline limestones and metamorphic schist-ophiolithe tectonic complex but does not interfere in the project, since the conglomerates are sufficiently thick, several tens of meters.

The material in the foundation zone is however erodible even under moderate hydraulic gradient of groundwater flow. For this reason, the foundation of the core must be done in deeper excavation levels, where conglomerates are tighter. A grout carpet will nevertheless be needed for this pur-

$\underline{\text { XLVII, No } 3-1767}$ 
pose, while the main impermeable grout curtain under the dam will complement protection against erosion.

Based on the in-situ permeability tests it is necessary to construct a grouting curtain, not deep though. Since it is not certain that the material will be easily injected the case of a diaphragm wall is considered in the design. The morphology in the area off the dam, in the abutments, together with the low permeability is adverse to favour groundwater seepage from detours. Only a small extension of the grout curtain is estimated to be sufficient. Drainage relief holes, downstream of the dam slope abutments are needed due to the low permeability of the material and the high water level that will be established downstream of the dam.

\section{Acknowledgments}

We would like to acknowledge the Hellenic Ministry of Rural Development and Food that supervised the geological design of Agiokampos dam, which is funded by the NSRF (National Strategic Reference Framework). Thanks are also given to "Sotiropoulos and Associates L.T.D." for the data provided.

\section{References}

Caputo R. and Pavlidis S. 1991. Neotectonics and structural evolution of Thessaly, Central Greece, Bull. Geol. Soc, of Greece, XXV/3, 119-133, Athens

Houlsby AC. 1976. Routine interpretation of the Lugeon Water test, Quarterly Journal of Engineering Geology, 9,303-313.

Migiros G. Vidakis M. Papazeti E. and Skourtsi-Koronaiou V. 1984. Geological Map of Agia Sheet, 1:50 000, IGME, Athens.

Schleiss J.and Pougatsch H. 2010. Les barrages. Du projet à la mise en service, Presses Polytechniques et Universitaires Romandes. EPFL, vol. 17.

Stamatis G. and Migiros G. 2004. The relationship between fractured tectonics and groundwater reservoir of massive formations of Ossa mountain (East Thessaly, Greece), Proceedings of the 10th International Congress of Geological Society of Greece, Thessaloniki, 2077-2086 (in Greek). 